\title{
A CONSTRUÇÃO JURÍDICA DE UMA POLITICA DE NOTÁVEIS: O JOGO DUPLO DA ELITE DO JUDICIÁRIO INDIANO NO MERCADO DA VIRTUDE CIVICA*
}

\section{THE LEGAL CONSTRUCTION OF A POLITICS OF NOTABLES: THE DOUBLE GAME OF THE PATRICIANS OF THE INDIAN BAR IN THE MARKET OF CIVIC VIRTUE}

\author{
Yves Dezalay** \\ Bryant Garth***
}

Fortemente marcado por sua história colonial, o campo jurídico indiano ilustra, de modo exemplar, os efeitos de uma imbricação estreita entre direito e política. Mesmo que os juristas-politicos tenham sido os pais do Estado indiano, foi um deles - Jawarharlal Nehru - que os acusou de desviar em proveito próprio os grandes princípios constitucionais. Com efeito, a elite do Judiciário se mobilizou contra a reforma agrária, usando seu savoir-faire político e, ao mesmo tempo, os recursos legais para defender os interesses de uma clientela de notáveis, com os quais se identificava mais por também pertencer a esse grupo. É fato que, mais tarde, ao de- fender as liberdades civis durante o estado de emergência instaurado por Indira Gandhi (Emergency), o Judiciário conseguiu resgatar sua imagem pública, mas não recuperou as posições perdidas no campo político. A Corte Suprema, por sua vez, lançou-se em um ativismo judiciário a favor dos mais desfavorecidos, antes de se envolver na defesa do meio ambiente e na luta contra a corrupção - o que lhe vale hoje ser reconhecida como árbitro legítimo dos conflitos entre políticos. Assim, a afırmação da autonomia do direito pode se revelar como corolário, senão como efeito do enfraquecimento da posição dos juristas no campo do poder de Estado.

\footnotetext{
* Originalmente publicado na Revista Genèses, n 45, dezembro de 2001, p. 69-90. Tradução de Patrícia Reuillard. Revisão técnica de Igor Gastal Grill.

** É doutor em sociologia, membro estatutário do Centre Européen de Sociologie et de Science Politique (CSE-EHESS, Paris/FR), diretor de pesquisa emérito do Centre National de la Recherche Scientifique (CNRS, Paris/FR). dezalay@msh-paris.fr.

*** É PH.D em direito, professor de direito na University of California (Irvine/EUA) e na Southwestern Law School (Los Angeles/EUA) e professor associado na American Bar Foundation (Chicago/EUA).bgarth@uci.law.edu.
} 
Para compreender esse paradoxo e essas reviravoltas, é essencial voltar à gênese colonial desta elite compradore ${ }^{1}$ do direito que construiu o Estado indiano. Nos primeiros anos da República, os herdeiros das linhagens de juristas, formados nos Inns of Courts do colonizador, colhem os frutos de seu envolvimento nas lutas da independência: formam o núcleo do campo político. Esse êxito excepcional também deve muito ao capital social e econômico herdado e que lhes permite converter a notoriedade profissional em capital político. Paradoxalmente, esse investimento da aristocracia do direito na construção do Estado se dá em detrimento da autonomia do campo jurídico, pois os mais aquinhoados ou mais ambiciosos entre eles têm todo interesse em preservar uma defınição da excelência profissional que lhes permita acumular posições concomitantes no direito, na economia e na política.

Hoje em dia, a situação não é mais a mesma. É verdade que os líderes do judiciário ainda pertencem a essa geração de notáveis que se ocupava simultaneamente do direito e da política. Mas esse jogo duplo se tornou muito mais difícil e arriscado, visto que a autonomia do campo político se construiu em torno de ideologias - como o desenvolvimentismo ou o hinduísmo - bem diferentes, senão opostas àquelas do direito fortemente marcado pelas ambiguidades e conluios de uma elite colonial. 0 modo de reprodução familiar que garantia a homogeneidade social dos notáveis do Judiciário não se adapta bem à competição escolar que agora prevalece no mercado dos saberes de Estado. Além disso, esse habitus aristocrático não convém muito a lutas políticas exacerbadas por um excesso populista e tradicionalista. Chega-se, assim, a uma situação paradoxal: para preservar posições cada vez mais ameaçadas no campo do poder, as elites políticas do campo jurídico não têm outra solução a não ser reforçar as instituições - como a Corte Suprema - sobre as quais repousa a afırmação da autonomia do jurídico e de sua distância do político. Levando-as a se distanciarem dos profissionais da política, essa estratégia de investimento no direito as coloca em posição de árbitro, tornando mais difícil o acúmulo de papeis e o jogo duplo que lhes valera prosperidade e prestígio.

A análise das relações entre o jurídico e o político deve se inscrever, portanto, em uma abordagem de história social. 0 savoir-faire dos juristas não se converte automaticamente em capital político. Convém investigar as determinações sociológicas que pesam sobre a estruturação do campo jurídico, assim como sobre a das instituições e dos saberes de Estado². Para compreender a imbricação desses dois lugares de poder, é necessário partir das

1. Usamos esse termo, que designava os nativos que atuavam como intermediários para os mercadores coloniais, para lembrar que os herdeiros da elite local, formados nas escolas de direito europeias, exerceram um papel similar no plano político, tanto na Ásia quanto na América Latina. Ver Yves Dezalay, Bryant Garth, The Internationalization of Palace Wars: Lawyers, Economists and the Contest to Transform Latin American States, Chicago, University of Chicago Press, 2002.

2. Para ser completa, essa abordagem deveria também levar em conta a concorrência com outros saberes do Estado, como a economia, e insistir muito mais do que o fazemos aqui nas relações entre os lawyers e o mundo dos negócios. Como exemplo, ver Y. Dezalay, B. Garth, The Internationalization of Palace Wars..., op. cit.; "Law, Lawyers and Social Capital: "Rule of Law" versus Relational Capitalism”, Social and Legal 
estratégias de reprodução das elites que neles atuam em paralelo, até mesmo de modo complementar, pois a transmissão familiar de um capital de notoriedade jurí- dica representou por muito tempo uma das vias privilegiadas de acesso ao campo do poder e um dos recursos mais valorizados no mercado da virtude cívica.

\begin{tabular}{|l|}
\hline A investigação \\
\hline Nosso método de pesquisa repousa essencialmente em entrevistas biográficas (fizemos um pou- \\
co mais de cem) com os principais representantes dos diferentes saberes (como o direito e a econo- \\
mia) e com indivíduos que ocupam cargos institucionais (advogados, acadêmicos, administradores, \\
políticos, dirigentes de ONGs, jornalistas, etc.), cujas estratégias contribuem para estruturar o cam- \\
po dos agentes públicos. Essas entrevistas permitem coletar informações muito pessoais sobre as ori- \\
gens sociais, redes familiares, trajetórias profissionais, alianças e oposições. Nosso primeiro objeti- \\
vo é esboçar uma espécie de cartografia das posições neste campo, em função dos diferentes tipos de \\
capital social mobilizados. Assim, ressaltando a importância do capital familiar, geralmente oculta- \\
da nos discursos profissionais, essas biografias permitem a releitura em termos estratégicos de toda \\
uma produção científica que visa a reforçar - ou questionar - a hierarquia das práticas jurídicas (ou \\
econômicas) e sua inscrição no campo dos saberes e dos poderes de Estado. Esse tipo de investigação, \\
que deve continuar em outros países da Ásia, foi aplicado à América Latina. Ver Y. Dezalay, B. Gar- \\
th, The Internacionalization of Palace Wars..., op. cit.
\end{tabular}

Para tentar minimizar os efeitos de objetivação inscritos tanto nas instituições jurídicas quanto nas lógicas de Estado ${ }^{3}$, as descrições que seguem buscam elucidar as estruturas do campo profissional por meio da história social que contribuiu para produzi-las, antes de redefini-las permanentemente. Para apreender a dinâmica política dessa história estrutural, privilegiamos três sequências cruciais:

- A primeira é de longe a mais importante; pois as estratégias familiares de promoção de uma elite compradore esclarecem a gênese colonial do Judiciário indiano e, ao mesmo tempo, o êxito de suas estratégias estatais.
- 0 recrutamento social do Judiciário esclarece também o jogo duplo desses juristas políticos: em nome da defesa dos interesses dos latifundiários, eles instigam a Corte Suprema a mobilizar a Constituição para afırmar sua autonomia em relação ao político. Essas contradições culminaram com a proclamação do estado de emergência em 1975: os juristas políticos se agrupam em torno do Judiciário para denunciar esse golpe de estado contra as liberdades constitucionais.

- A derrota de Indira Gandhi, em 1977, e o fracasso da tentativa de restauração da hegemonia dos juristas políticos abrem caminho para uma recomposição da divisão do trabalho, que se torna mais complexa

Studies, vol. 6, no 1, 1997, p. 109-143. Ver também: Christophe Charle, "Pour une histoire sociale des professions juridiques à l'époque contemporaine: note pour une recherche”, Actes de la recherche en sciences sociales, no 76-77, 1989. Victor Karady, "Une nation de juristes: des usages sociaux de la formation de juriste dans la Hongrie d'ancien régime”, Actes de la recherche en sciences sociales, n 86-87, 1991.

3. Sobre a violência simbólica dessas lógicas de Estado, ver Pierre Bourdieu: "Esprits d'État; Genèse et structure du champ bureaucratique”, in Raisons pratiques. Sur la théorie de l'action, Paris, Le Seuil, 1994. 
tanto no campo jurídico como no campo do poder de Estado. A instância superior da Justiça se afirma como árbitro de um jogo político do qual os notáveis do Judiciário se distanciaram, pois agora abraçam a causa da internacionalização.

\section{De uma geração à outra: dois modelos de excelência}

Para ilustrar de modo mais explícito as hipóteses que acabam de ser evocadas, basta comparar as trajetórias de duas gerações sucessivas em uma linhagem familiar de notários do judiciário.

P., que foi Chief Justice of India antes de ser nomeado para a Corte Internacional de Justiça de Haia, é filho de um lawyer que termina sua carreira como vice-presidente da Índia, depois de ter sido um conselheiro próximo de Jawarharlal Nehru e ministro da justiça de Indira Gandhi. Entretanto, antes de começar uma carreira de Estado, o pai sobe todos os escalões de uma carreira jurídica típica. Não vindo de uma família de lawyers e apesar de uma trajetória escolar brilhante, coroada por um master em Cambridge, ele tem de começar pela base da pirâmide judiciária, nas District Courts, no início dos anos vinte. A notoriedade adquirida junto aos colegas permite que ele se instale, alguns anos mais tarde, como barrister na High Court; em 1945, é indicado para o cargo de juiz, coroação de uma carreira próspera como advogado, consagrada essencialmente à defesa dos interesses dos latifundiários. Pouco depois, sua trajetória se direciona para a política: Nehru - que ele não conhece pessoalmente, embora sejam da mesma cidade - lhe pede que faça parte da delegação indiana na ONU. Nos anos seguintes, leva simultaneamente uma carreira de diplomata - como enviado especial e conselheiro de Nehru - e de político, eleito para o Senado, ministro da justiça, governador do Karnataka e, finalmente, Chairman of the Upper House e Vice-President of India (1969-1974), ao mesmo tempo que atua como barrister na Corte Suprema. Recusa, aliás, ser nomeado como Justice (juiz da Corte Suprema), pois considera a corte como uma "gaiola dourada", ainda que se apresente como "mais [como] um jurista conservador do que um político".

Em contrapartida, seu filho se define de saida como um herdeiro da tradição britânica na qual, diz ele, "os juizes devem ser tão discretos quanto eminentes; sobretudo, devem se manter à distância da mídia” (entrevista). 0 início de sua carreira é facilitado pela notoriedade de seu pai: após um rápido estágio junto a um senior renomado, ele se orienta para um novo contencioso em pleno desenvolvimento, o direito fiscal e o direito comercial. Seu escritório de advocacia prospera rapidamente e, aos 33 anos, já emprega sete juniors. Entretanto, noblesse oblige, não hesita muito quando lhe oferecem um posto de juiz com a idade excepcionalmente precoce de 36 anos, ainda que essa promoção divida sua renda por cinco... Em seguida, sobe - muito rápido - todos os escalões da hierarquia judiciária até a Corte Suprema (1978), da qual se torna, de acordo com o critério da antiguidade, Chief Justice em 1986. Ele contribui para moderar o ativismo de seu antecessor que, aos olhos da corrente moderada, "foi longe demais e rápido demais [...] fez demais em muitas ocasiões [...], o que abalou a confiança do público na imparcialidade da Justiça” (entrevista). Em uma coletânea de ensaios em homenagem a um advogado famoso, constitucionalista e diretor do grupo industrial Tata, ele ressalta, aliás, que é perigoso para a Corte se aventurar em terreno político. Em 1989, por solicitação do primeiro-ministro, aceita um cargo no Tribunal de Haia. Ao final desse triplo percurso de fiscalista, Chief Justice e juiz internacional, ele se torna muito naturalmente um árbitro internacional renomado ${ }^{4}$. E dois de seus filhos são hoje partners em firmas jurídicas internacionais.

Mais do que multiplicar exemplos, pode-se mencionar mais brevemente outra dessas trajetórias familiares, menos excepcional, mas igualmente representativa do Direito comercial de Bombaim. Filho mais velho de um comerciante abastado, ele tinha a ambição de fazer política. Partiu, portanto, para Oxford para estudar direito e história. Nesse meio tempo, seu pai faliu e, ao voltar para a Índia, ele teve de renunciar - temporariamente - à política para começar com dificuldade (pois não tinha apoio familiar) uma carreira no direito. Após uma brilhante trajetória que o levou a ser escolhido por seus pares para liderar a banca de Bombaim, é nomeado Chief Justice e, depois, embaixador em Washington. Seu filho seguiu suas pegadas, pois, após estudar direito e história em Cambridge,

4. Y. Dezalay, B. Garth, Dealing in Virtue, Chicago, University of Chicago Press, 1986. 
foi reeleito por três vezes presidente do prestigioso Bombay Bar Association, que reúne os advogados especializados nos grandes casos comerciais submetidos diretamente à Bombay High Court. Entretanto, contrariamente a seu pai, ele não aspira a funções públicas. Sua intervenção no campo político se limita a influir na política do direito - o que, no contexto atual de abertura econômica, não é pouca coisa.

Deste modo, em ambos os casos, as carreiras da segunda geração são marcadas por um retorno ao direito. Isso se explica em grande parte, é verdade, pelo aumento e diversificação da oferta no mercado das elites de Estado. A relativa penúria de profissionais cosmopolitas nos primeiros anos da independência representava uma oportunidade excepcional para se lançar em uma segunda carreira política ou diplomática. Hoje, em contrapartida, a profissionalização dessas carreiras de Estado torna mais difícil seu acesso aos não especialistas, que só podem avançar seu capital social de figuras notáveis do judiciário.

Entretanto, a concorrência de novas competências de Estado não explica tudo. Talvez essas elites polivalentes tenham perdido sua preeminência no campo político porque não diversificaram a tempo suas estratégias e alianças. Como na época colonial, esses notáveis do direito continuaram a defender essencialmente os interesses financeiros das famílias de latifundiários e de comerciantes compradore; também sofreram o contrapé da política de desenvolvimento e de justiça social que se impunha a esse novo Estado. Antes de analisar as peripécias dessa história política do judiciário, convém resgatar a gênese colonial dessas estratégias de jogo duplo.

\section{Da aprendizagem de um direito colonial à construção do Estado: a trajetória de uma elite compradore}

Como mostrou Pierre Bourdieu ${ }^{5}$, não se podem analisar as lutas internas de construção de um campo profissional, limitando-se a defınições institucionais que contribuem para ocultá-las, mesmo que decorram delas. 0 resgate da gênese do campo é essencial para não cair na armadilha dessas representações falsamente objetivas, como a noção de "judiciário”, que tende a mas- carar a extraordinária estratificação desse meio profissional, assim como a importância determinante da herança familiar. As análises que seguem só tratam, portanto, das instâncias superiores do Judiciário, pois essa hierarquia instituída pelo colonizador permanece muito forte a despeito das leis que visam aboli-la ${ }^{6}$. Esse subconjunto agrupa essencialmente os advocates da Corte Suprema ${ }^{7}$ e as mais antigas e mais prestigiosas High Courts da época colonial - Bombaim, Madras, Calcutá - que constituem o viveiro de reprodução dos membros

5. Bourdieu, "La force du droit, Éléments pour une sociologie du champ juridique”, Actes de la recherche en sciences sociales, no 64, p. 5-19, 1986; Réponses, Paris, Seuil, 1992, p. 207.

6. A estratificação do Judiciário foi formalmente abolida pelo Advocates Act de 1961 (Samuel Schmitthener, "A Sketch of the Development of the Legal Profession in India", Law \&t Society Review, vol. 3, no 2, 1968-1969, p. 360), que institui um All India Bar, tolerando, provisoriamente, a sobrevivência da distinção colonial entre barristers e solicitors nas grandes bancas de Mumbai e de Calcutá, onde subsiste de fato uma diferenciação entre instância superior e inferior. Os grandes casos, essencialmente comerciais, podem vir diretamente à High Court, que funciona paralelamente como instância de apelação para casos mais rotineiros. É desnecessário dizer que essa tolerância perdura. Ainda hoje, essas duas instâncias andam lado a lado sem se misturar. Sua organização profissional e seus pontos de encontro são bem diferentes. Segundo um de nossos interlocutores, uma conserva a aura de um clube britânico, com grandes poltronas de couro, enquanto a outra se contenta com bancos de madeira sem encosto.

7. A Corte Suprema tem pouco menos de 4.000 membros, em relação aos quase 600.000 lawyers que a Índia teria, de acordo com a estimativa feita pelo atual Law Minister. Ainda que também considerássemos a 
das instâncias superiores ${ }^{8}$. Com efeito, assim como no modelo britânico, os juizes da Corte Suprema são recrutados na elite dos Queen's Counsel (QC), cuja nomeação representa a coroação da trajetória profissional. Como veremos mais adiante, é muito recente a implantação de uma espécie de divisão simbólica do trabalho, onde a figura do juiz do Supremo se opõe à da figura do notável-político, ao mesmo tempo que a complementa, para encarnar a distância, a reserva e a neutralidade de um árbitro dos conflitos sociais.

0 resgate da história colonial também é esclarecedor do ponto de vista das relações entre direito e política, pois a abertura progressiva da última instância do Judiciário a indianos tangia simultaneamente a uma lógica de promoção profissional e a um projeto político de construção de uma aristocracia compradore. Com efeito, várias vias de acesso coexistiam: a "porta dos fundos” permitia a promoção interna de pequeno número de profıssionais em jurisdições nativas (vakils e indian pleaders), enquanto a "porta principal" dos Inns of Courts era reservada aos herdeiros das classes possui- doras. "Ainda que poucos indianos tivessem meios para financiar o longo programa de formação para os futuros barristers, que só existia na Grã-Bretanha, as primeiras gerações de candidatos eram essencialmente de ricos comerciantes pársis ${ }^{9}$." Essa passagem pela metrópole era tão prestigiosa quanto pouco exigente do ponto de vista escolar. 0 exame que permitia o acesso aos Inns of Court tinha a fama de ser menos difícil do que os das escolas indianas de direito e, mais ainda, do que aquele - muito seletivo - do Indian Civil Service. Assim, os herdeiros das classes possuidoras eram "chamados ao Judiciário" e voltavam à Índia, transformados em English gentlemen ${ }^{10}$. No entanto, esses herdeiros não escapavam ao estágio junto a um senior, o que representava uma barreira extra para entrar nesse mercado, tanto mais rentável quanto protegido.

A formação dos produtores de direito sempre foi - e permanece - um assunto de família. "Era em casa que as tradições profissionais eram inculcadas. [...] Não podendo contar com o apoio de um parente já estabelecido no Judiciário, os jovens lawyers mais bem treinados ou mais talentosos

elite das principais bancas, principalmente a de Mumbai, estimamos que esse pequeno grupo que fala em nome do judiciário não represente mais do que $1 \%$ dos advogados.

8. Se comparados às abordagens usuais da história ou da sociologia, os limites bastante fluidos dessa definição podem chocar. No entanto, esses limites estão de acordo com a noção de um campo, com seu núcleo duro e suas fronteiras, porosas e instáveis. 0 principal interesse heurístico de uma conceptualização como esta é de chamar atenção para o que está em jogo precisamente nas margens de um campo profissional, pois é exatamente aí que podemos observar a mobilidade das pessoas e a circulação dos recursos sociais ou financeiros entre o campo jurídico e os campos do poder econômico ou político, que as representações institucionais tendem a ocultar.

9. S. Schmitthener, “A Sketch of the Development of the Legal Profession in India”, Law \& Society Review, vol. 3, no 2, 1968-1969, p. 365. De fato, as estadias eram longas, pois, antes mesmo de serem admitidos pelos Inns, a maioria dos estudantes indianos estudava na Grã-Bretanha por quatro ou cinco anos.

10. Ibid., p. 369. 
tinham poucas oportunidades de mostrar sua competência ${ }^{11}$." Causa muita surpresa, aliás, a extraordinária continuidade do modo de recrutamento dessa elite profissional ${ }^{12}$, pois essa situação perdura até hoje. A grande maioria de nossos interlocutores particularmente aqueles que ocupam altos cargos no Judiciário e nas instâncias superiores - são herdeiros que se vangloriam de uma longa ascendência de magistrados.

0 apoio familiar é decisivo, sobretudo para o aprendizado nas chambers de um senior renomado. "Ter recebido sua formação em chambers de renome é fator determinante para ter sucesso no Direito. [...] E é nesse nível que o apoio familiar é decisivo. Quando um colega lhe pede para aceitar o filho como estagiário, é muito difícil recusar. É aí que tudo se dá..." (entrevista). Evidentemente, esse estágio não é remunerado nos primeiros anos - o que aumenta mais ainda, como observara Richard L. Abel, uma seleção social em que os recursos familiares têm o mesmo peso que o conhecimento e o talento pessoais ${ }^{13}$.

A continuidade da carreira não faz senão ampliar essa defasagem inicial entre os herdeiros e os recém-chegados. Por menos talento que tenham, aqueles vão logo se familiarizar com a elite do Judiciário e, progressivamente, se dar a conhecer não somente aos juízes da Corte Suprema ${ }^{14}$, mas também aos solicitors, que podem lhes confiar grandes casos que permitem a construção de notoriedade pessoal. Esse processo é rapidamente cumulativo: o renome adquirido nessas grandes defesas não somente atrai os clientes ou os pares que podem encaminhar a outros trabalhos frutíferos, como também desperta a atenção dos seniors advocates e dos juízes que controlam o acesso à prestigiosa Corte Suprema.

Em entrevista, um dos presidentes da Corte Suprema, que fora eleito presidente da União Internacional dos Advogados em 1996, contou-nos como se tornou senior advocate, após cerca de quinze anos de prática:

Sua nomeação como QC (Queen's Counsel) depende de sua reputação no judiciário. Quando os colegas começam a apelar cada vez mais a você para apresentar seus processos à Corte Suprema, isso significa que confram na reputação que você adquiriu na Cor-

11. Ibid., p. 375.

12. Já nos anos 1960, S. Schmittener se espanta ao perceber que apenas reproduzia observações feitas na metade do século XIX a respeito da banca de Madras.

13. Ver Richard L. Abel, "England and Wales: A Comparison of the Professional Projects of Barristers and Solicitors", in R. Abel, Philip S. Lewis (ed.), Lawyers in Society, The Common Law World, Berkeley; University of California Press, 1988. Ver também: Joginder S. Gandhi, "Past and Present: A Sociological Portrait of the Indian Legal Profession”, in R. L. Abel, Ph. S. Lewis (ed.), Lawyers in Society, The Common Law World, Berkeley, University of California Press, 1988, p. 376.

14. Evidentemente, é ainda mais fácil quando o jovem barrister vem de uma família em que há um ou dois juízes - o que não é raro, considerando a endogamia do meio e o modo de recrutamento da Corte Suprema. Segundo um de nossos interlocutores, ele próprio um Chief Justice, "é o que chamamos aqui de justiça pela cara do advogado (face law)", pois os argumentos de uma defesa são mais bem aceitos quando dirigidos a um juiz que é também um parente". 
te, lidando com casos bem distintos. [...] Diferentemente de meus colegas, eu tinha a oportunidade de atuar na Corte. Eu tinha publicado, em suma, era conhecido.

Deve-se esclarecer também que seu pai, diplomado pela Lincoln Inn, ficara muito célebre nos anos 1950 por ter defendido um líder comunista preso, em um dos primeiros grandes processos constitucionais.

\section{1. "Nababos" do direito comercial}

Essa dupla seleção pelo dinheiro e pelo meio familiar está de acordo a lógica dessa instância superior da justiça estreitamente inserida no mundo dos negócios. Desde sempre, os honorários foram exorbitantes: no século XIX, estimava-se que eram sete vezes mais altos do que na Grã-Bretanha ${ }^{15}$. Os barristers que aceitavam se expatriar ganhavam fortunas, que gastavam igualmente rápido, pois esses gentlemen attorneys precisavam manter o ritmo de vida luxuoso de sua rica clientela (comerciantes ricos e banqueiros informais indianos). "O prestígio de um lawyer depende de sua hospitalidade, boas maneiras e círculo de amigos que ele estabelece ${ }^{16}$."

Essa situação que garante aos comerciantes uma justiça sob medida, com profissionais tão competentes quanto atenciosos, não muda muito com a chegada - a conta-gotas - de jovens barris- ters indianos que tudo predispunha a se tornarem gentlemen do Direito. Seguindo o exemplo dos seniors que supostamente lhes "ensinar[am] a excelência das tradições britânicas”, eles logo aprenderam a se valer de seu monopólio para enriquecer espetacularmente. A tal ponto que a exposição de sua riqueza lhes valeu o apelido de “nababos do Direito". Assim, nos anos 1880, quando ainda estava na casa dos 30 anos de idade, Motilal, o pai de Jawarharlal Nehru, "vivia como um príncipe em um verdadeiro palácio e possuía os primeiríssimos automóveis” ${ }^{17}$. De maneira geral, o mercado do direito sempre foi extraordinariamente próspero: os processos eram numerosos - 2,2 milhões em 1901 - principalmente devido aos litígios suscitados pelo sistema de grandes propriedades (zamindari), e se prolongavam eternamente, durando com frequência uma geração.

\subsection{Uma estratégia moderada de indiani- zação em proveito de uma elite anglicizada}

Se, como observara Max Weber, a adoção do modelo britânico de produção dos bens de justiça está de acordo com uma lógica mercantil, sua “indianização” responde também a preocupações políticas específicas da relação colonial. Embora as instituições jurídicas estivessem no cerne do dispositivo imperial ${ }^{18}$, elas também desempenharam um papel central em uma transmissão do poder colonial

15. S. Schmitthener, "A Sketch...”, op. cit., p. 346.

16. Ibid., p. 348.

17. Ibid., p. 370. Ver também a excelente biografia da família Nehru: Jad Adams et Phillip Whitehead, The Dynasty, The Nehru-Gandhi story, Londres, Penguin, 1997, p. 9 e ss.

18. "A Índia se tornou um laboratório para as reformas judiciárias inspiradas pelo pensamento liberal" (whiggish). Ver Rajeev Dhavan, “Judges and Indian Democracy: the Lesser Evil?”, in Francine R. Frankel et al., Transforming India, Social and Political Dynamics of Democracy, New Dehli, Oxford University Press, 2000, p. 317. "Para a maioria dos britânicos, a instauração de uma rule of law no continente india- 
que, de ambos os lados, se esforçou para não questionar nem as regras do mercado nem as hierarquias sociais. A estabilidade das instituições jurídicas se mostrava como uma das melhores garantias de uma mudança na continuidade $^{19}$. Essa estratégia não tem nada de surpreendente, pois a elite indiana do direito foi a principal beneficiária dessa transferência dos poderes que ela programou - mas para a qual também fora programada.

0 aprendizado do direito faz parte, desde o início, de um projeto político: a construção de uma elite nacional, viveiro de futuros líderes. A formação jurídica era considerada a melhor preparação para uma carreira política ${ }^{20}$. Essas ambições foram encorajadas, senão suscitadas, pelos líderes de grupos sociais como os pársis, que representavam a elite esclarecida da classe comerciante $^{21}$. "Como grupo profissional com vocação para reunir o essencial das elites do país, a profıssão jurídica dominou o espaço público. Eram lawyers que organizavam e administravam as instituições educativas e filantrópicas ou as sociedades caritativas $^{22}$." Enquanto esperava que essa estratégia política de longo fôlego produzisse seus efeitos, o Judiciário permitia a essa elite reformista prosperar, ao mesmo tempo que defendia os interesses de seus mandatos em face das exigências da burocracia colonial. Com efeito, tendo aprendido na escola do colonizador, esses Indian gentlemen estavam muito bem colocados para usar contra ele as contradições ou as ambiguidades de um sistema judiciário que precisava se mostrar independente e crivel aos indianos, já que esse Vakil Raj ${ }^{23}$ visava precisamente tornar mais legítima a dominação que eles sofriam ${ }^{24}$.

0 Indian National Congress, fundado em 1885, foi o principal suporte de uma estratégia de reformismo constitucional, concebida e liderada por elites jurídicas anglicizadas ${ }^{25}$.

no foi considerada provavelmente um dos êxitos do British raj de que eles mais se orgulham”, Lloyd I. Rudolph, Susanne Hoeber Rudolph, "Barristers and Brahmans in India", in In Pursuit of Lakshmi, The Political Economy of the Indian State, Chicago, University of Chicago Press, 1987, p. 34.

19. "Curiosamente, o movimento pela independência quase não lutou por mudanças radicais no sistema jurídico. [...] Contentamo-nos em 'nativizar' o topo da pirâmide judiciária.", R. Dhavan, “Judges...”, op. cit., p. 319.

20. Ver S. Schmitthener, “A Sketch...”, op. cit., p. 372 e 378.

21. "Ao tomar consciência do potencial que os barristers tinham para dirigir a sociedade indiana, um dos líderes pársis mais visionários abriu um fundo para financiar essa aprendizagem. [...] A profissão de advogado era vista como um dos caminhos naturais para o avanço da nação indiana. Esperanças que foram largamente realizadas... [...]" (ibid., p. 366).

22. Ibid, p. 372.

23. Essa denominação derrogatória era dada pelos colonos britânicos para denunciar o acesso muito fácil dos indianos às jurisdições em que seus mandatários (Vakil) tinham se transformado em mestres do direito.

24. Ver R. Dhavan, “Judges...”, op. cit., p. 318. A análise feita por Edward P. Thompson (Whigs and Hunters, Londres, Allen Lane, 1975) das contradições inerentes a uma justiça que participa de uma dominação simbólica vale, com mais razão ainda, na relação colonial.

25. "O Partido do Congresso começou com a união de elites regionais anglicizadas que tinham, sobretudo, interesses e um estilo de vida em comum, que as distinguiam profundamente da grande maioria dos 
Devido à sua educação ocidental e formação jurídica, os líderes do Partido do Congresso estavam totalmente à vontade com os procedimentos parlamentares e os debates constitucionais. Eles tinham confiança na tradição britânica de justiça. [...] Segundo sua biografia, Motilal Nehru era um moderado, menos favorável ainda às teses dos extremistas porque estava convencido de que um advogado de talento podia se fazer ouvir tão facilmente na tribuna da opinião britânica quanto naquela da Allahabad High Court ${ }^{26}$."

Com certeza, a moderação dessas reivindicações não bastou para prevenir os conflitos, e a intensificação das lutas levou alguns desses nababos do direito, dentre os quais Motilal, a renunciar às suas posições duplamente privilegiadas para seguir Indira Gandhi em sua estratégia de boicote às instituições jurídicas e políticas coloniais ${ }^{27}$. As exigências da política tinham se tornado tais que aceitavam mal o amadorismo dessa elite compradore cujos múltiplos papeis facilitavam o jogo duplo.

Motilal, Das, Rajagopachari e muitos outros lawyers sacrificaram seus ganhos principescos e renunciaram a seus mandatos legislativos para começar a viver na simplicidade e na austeridade. [...] A partir dos anos vinte, continuam sendo os lawyers que fornecem todos os dirigentes políticos, mas eles não estão mais na ativa. É fato que eram juristas - e até mesmo juristas muito renomados -, mas não tinham hesitado em sacrificar sua carreira profissional para se devotar integralmente ao interesse nacional ${ }^{28}$.

Mesmo que, nesse caso, esse "sacrifício" revelasse, sobretudo, a prioridade dada às ambições políticas sobre a continuação de uma profissão que, aliás, lhes proporcionara tudo o que podiam esperar dela - principalmente o acúmulo de recursos financeiros, indispensável para investir na política, mudando a imagem de nababo anglicizado por aquela de um asceta a serviço da coletividade indiana ${ }^{29}$.

\section{0 investimento nas instituições de direi- to como estratégia política}

\subsection{Dos políticos aos grandes sacerdotes do direito: confusão de papéis e divisão do trabalho simbólico}

Os primeiros anos da independência marcaram o apogeu de um Judiciário que vê seu mercado profissional se tornar ainda mais proveitoso devido ao êxito espetacular de seus investimentos políticos. No entanto, esse êxito foi tão excepcional quanto breve. Desde os anos sessenta, a imagem pública do Judiciário começou a periclitar.

indianos que elas pretendiam representar.” L. I. Rudolph, S. Hoeber Rudolph, In Pursuit..., op. cit., p. 127. J. Adams e Ph. Whitehead, (The Dynasty..., op. cit., p. 25) sugerem que um dos principais objetivos dos fundadores do Congress também era conseguir que a aristocracia imperial, que os ignorava, reconhecesse os méritos dessa nova classe de profissionais, em prol de uma política colonial que se apoiasse e arranjos feitos diretamente com as famílias reinantes dos estados principescos.

26. S. Schmitthener, “A sketch...”, op. cit., p. 378.

27. Ver J. Adams et Ph. Whitehead, The Dynasty..., op. cit., p. 54 e ss.

28. Ibid., p. 380 e 381.

29. De fato, poderíamos aplicar a muitos desses ascetas da política o comentário elegantemente irônico feito pela filha de Mahatma Gandhi: "Se meu pai soubesse como custa caro mantê-lo na pobreza!" 
0 judiciário não oferece mais a atividade mais honrosa e proveitosa da Índia. Essa carreira não atrai mais os melhores estudantes e não domina mais a vida política e social do país. Ela perdeu o monopólio das elites dirigentes que durou um século ${ }^{30}$.

Esse relativo declínio não se deve somente à concorrência de novos saberes de Estado, como a economia, cujo desenvolvimento foi favorecido pelas políticas de desenvolvimento. Ele se explica também pela prioridade dada a essas políticas pelo novo Estado indiano - pelo impulso pessoal de Jawarharlal Nehru - que desvela todas as ambiguidades do acúmulo de posições dos juristas-políticos. De fato, enquanto advogados dos latifundiários, eles são levados a se opor à reforma agrária, ao passo que esta constitui a pedra angular da estratégia de modernização e de progresso social, pregada oficialmente pelo Partido do Congresso, onde eles ainda ocupam posições muito influentes. É verdade que esse papel duplo se revela muito proveitoso em um primeiro momento; porém, ao se perpetuar, essa estratégia de jogo duplo tem seus riscos: tanto para a credibilidade social da justiça, quanto para a pretensão da elite do Judiciário de encarnar o interesse nacional.
Com efeito, embora os líderes do Congress - como Indira Gandhi, Jawarharlal Nehru ou Patel - tenham renunciado à advocacia pela carreira política, esse exemplo quase não foi seguido pela grande maioria dos juristas-políticos.

A fronteira entre esses dois universos com exigências contraditórias permaneceu, por muito tempo, tão imprecisa quanto porosa. A maioria dos lawyers que se envolvia na política ou nas questões de Estado continuava a cultivar cuidadosamente seus laços com o judiciário. Ainda hoje, de resto, esses vaivéns são numerosos, pois essa dupla atividade é tão proveitosa quanto conforme ao modelo de excelência do judiciário ${ }^{31}$, tal como fora definido havia quase um século por - e para - os juristas fundadores do Indian National Congress. Ora, mesmo se envolvendo na política, esse meio profissional ficou profundamente marcado por todo um habitus elitista e um nível de vida que reforçam seus vínculos com as classes possuidoras $^{32}$, mais ou menos diretamente ameaçadas pela reforma agrária e pelo enquadramento burocrático, até mesmo a privatização da produção industrial. Consequentemente, era inevitável que essa elite do Judiciário mobilizasse todos os recursos legais em um combate político, onde ela

30. Ibid., p. 382. Com certeza, esse diagnóstico pessimista foi incontestavelmente influenciado pelas orientações ideológicas dos missionários do law \&t development que, antes de se dissociar deles, compartilhavam a ideologia dos promotores das políticas de desenvolvimento, principalmente suas críticas a um judiciário acusado de mobilizar todos os recursos legais para frear os projetos de reforma agrária.

31. Um desses senior advocates, líder do Judiciário antes de ser ministro, considera muito natural que as figuras eminentes do Judiciário continuem sua carreira na política graças a seu domínio na linguagem: "Quando se tem o domínio do verbo de um bom advogado, não há nada mais natural do que querer levar suas ambições para uma tribuna bem mais ampla, a arena política. 0 Judiciário é um trampolim natural para a política." (entrevista).

32. "A profissão jurídica não fez senão responder às demandas dos clientes que tinham condições de pagá-la. Ela se colocou a serviço do grupo que tinha os principais interesses a proteger: os latifundiários”, Herbert C. L. Merillat, "Law and Land Reform in India”, Law \&t Society Review, vol. 3, no 2, 1968-1969, p. 295-299. 
representava seus próprios interesses e, ao mesmo tempo, os de seus clientes. Em contrapartida, essa instrumentalização do direito só podia colocar em perigo a legitimidade das jurisdições, pois os juízes eram ligados demais ao Judiciário para que não se percebesse que tomavam partido nesse conflito social maior. A forte homogeneidade social desse meio profissional contribuía para reforçar a imagem de uma justiça parcial, totalmente a serviço das classes possuidoras.

Com efeito, assim como no modelo britânico, os membros da Corte Suprema são recrutados na elite do Judiciário, que ela também contribui para reproduzir. Definindo os critérios de excelência, os juízes têm uma grande influência sobre a notoriedade e a promoção na hierarquia profissional. Esse duplo sistema de interdependência garante não só grande homogeneidade, mas também grande estabilidade ${ }^{33}$.

Os juízes da Corte Suprema representam um dos arquétipos da excelência profissional. Eles encarnam a experiência e o distanciamento - virtudes essenciais da (juris)prudência. Como os notáveis do Judiciário, são ainda hoje herdeiros de uma elite compradore: oriundos de famílias brâmanes (metade deles ${ }^{34}$ ) e formados nos Inns of Court (a outra metade, que provém frequentemente de meios mais diversos). Antes de subir os degraus da carreira judiciária (em média, uma dezena de anos), eles começaram adquirindo notoriedade atuando na advocacia por cerca de vinte anos. Alguns deles não ficaram insensíveis aos atrativos do poder: cerca de um terço assumiram funções governamentais - government pleader, government advocate que, segundo nossos interlocutores, tanto abreviam a carreira quanto indicam o reconhecimento pelos políticos do campo. Mas, ao mesmo tempo, eles evitaram expor muito abertamente suas posições políticas $^{35}$. Ainda por cima, o modo de funcionamento - principalmente a promoção por antiguidade, que produz uma alta rotatividade dos Chief Justice - contribui para passar a imagem de juízes cuja individualidade se apaga em proveito de uma coletividade quase anônima, que supostamente encarna a autoridade do direito. Essa escolha de carreira, em que a honorabilidade é adquirida a preço de renúncias materiais ${ }^{36}$ e de uma submissão à disciplina coletiva, não convém muito às fortes personalidades do Judiciário. 0 ideal do juiz da Corte Suprema é o oposto, portanto, do carisma que seus colegas devem cultivar para fazer carreira na política.

33. Charles R. Epp fala de uma profissão que “avança tão rápido quanto uma geleira”'. Ver Ch. R. Epp, The Rights Revolution, Lawyers, activists and Supreme Courts in Comparative Perspective, Chicago, University of Chicago Press, 1998, p. 101. De fato, é impressionante ver que as observações feitas por George H. Gadbois J. R. em 1969 continuam perfeitamente atuais. Ver G. H. Gadbois J. R. "Indian Supreme Court Judges: A Portrait”, Law \& Society Review, vol. 3, no 2, 1968-1969, p. 317-337.

34. Essa porcentagem levantada por G. H. Gadbois nos anos 1960 permanece, vinte anos depois, idêntica, de acordo com J. S. Gandhi ("Past and...", op. cit., p. 376).

35. "0 juiz típico é um personagem apolítico que, ao longo de toda sua carreira, evitou se envolver abertamente em atividades políticas”, G. H. Gadbois, "Indian Supreme...”, op. cit., vol. 1, p. 330.

36. Essa defasagem entre as remunerações dos juizes da Corte Suprema e a renda dos líderes do Judiciário aumentou, a ponto de causar atualmente, segundo nos informaram, sérios problemas de recrutamento para as instâncias superiores. 
Disso resulta uma situação aparentemente paradoxal de um campo jurídico muito homogêneo socialmente e, ao mesmo tempo, estruturado em torno de dois polos que indicam duas concepções muito diferentes da excelência profissional: a de um notável da política e a do grande sacerdote distante das disputas políticas e midiáticas. Essas duas figuras da elite tiveram o mesmo aprendizado familiar e o mesmo percurso profissional, antes de tomar caminhos divergentes na segunda metade de sua carreira. Essas especializações tardias representam duas vias bem distintas para rentabilizar o capital de notoriedade acumulado na prática do direito. Entretanto, cada uma delas contribui à sua maneira para produzir e reproduzir o capital de legitimidade. Sua oposição manifesta faz parte assim de um jogo de papeis que se inscreve na divisão do trabalho simbólico de (re)produção da crença no direito. De resto, as biografias mostram bem que a fronteira continua tão imprecisa quanto porosa entre estratégias jurídicas e estratégias políticas. Assim, quando interrogados sobre os momentos determinantes de sua carreira, a maioria dos seniors barristers logo cita a "causa célebre" que deu início à sua notoriedade, que é, quase sempre, um caso político. De fato, essas defesas são mais passíveis de atrair a atenção dos seniors porque saem da rotina e levantam questões de direito constitucional, competência reservada da hierarquia do campo.

\subsection{As armas jurídicas de uma política de classe}

Quando, sob o impulso de Jawarharlal Nehru, o Partido do Congresso se lança em uma política de intervencionismo econômico e social, a elite do Judiciário se mobiliza para defender os interesses das classes possuidoras. Essa luta política é orquestrada mais facilmente no terreno jurisdicional porque os principais protagonistas - sobretudo os latifundiários - estão familiarizados com esse fórum, onde costumavam utilizar todos os recursos legais para se defender das usurpações da burocracia colonial ou de suas exigências fiscais. Mais uma vez, a questão é simultaneamente política e financeira: trata-se de determinar o nível de compensação dos zamindars ${ }^{37}$, cujas novas leis preveem a expropriação. Como a High Court julgara que essas leis violam o "princípio fundamental de igualdade diante da lei”, o governo responde com uma emenda constitucional (a primeira, 1951), que estabelece que essas leis de implantação da reforma agrária não são submetidas aos direitos fundamentais - emenda que os advogados dos zamindars se apressam em contestar como uma violação aos princípios fundamentais da Constituição.

Estes são os primeiros episódios de uma longa batalha que tem múltiplas repercussões - tanto jurídicas quanto políticas. A formulação dessa luta política em

37. H.C.L. Merillat os descreve como "latifundiários, frequentemente absenteístas e recebendo, em certos casos, rendas tão elevadas que levantavam protestos da parte dos fazendeiros explorados" ("Law and Land...”, op. cit., p. 295). 
termos jurídicos serve perfeitamente aos interesses das elites do Judiciário, que encontram aí uma formidável oportunidade para valorizar sua dupla função: primeiramente, vender - bem caro - à sua clientela um talento de processualista que se apoia em seu savoir-faire político; em segundo lugar, também mobilizar seu saber jurídico nas lutas internas no campo político ${ }^{38}$.

Devido a essa superoferta no campo constitucional, a Corte Suprema logo se encontra no centro dessas batalhas ${ }^{39}$. A maioria dos comentaristas que analisa as peripécias e os efeitos da história da judicial review $w^{40}$ a interpreta em termos de relação de forças entre o poder político e a autoridade judiciária. Lloyd e Suzanne Rudolph descrevem uma espécie de oscilação: após se ter mostrado relativamente complacente com um Partido do Congresso hegemônico e dominada pela forte personalidade de Jawarharlal Nehru, a Corte afirma sua autoridade constitucional quando o Partido racha e sofre suas primeiras derrotas eleitorais em $1967^{41}$. Em contrapartida, diante das ameaças de Indira Gandhi, a Corte assume posições muito mais prudentes e chega até a declarar válidos os atentados às liberdades após a proclamação do estado de emergência, em 1975 - uma renúncia denunciada como humilhante pelos líderes do Judiciário ${ }^{42}$. Por fim, última etapa desse movimento de pêndulo, o enfraquecimento do Partido do Congresso e a fragilidade das coalizões de governo favorecem a reafirmação solene do poder constitucional da Corte - e mais facilmente ainda porque a velha geração dos juristas-políticos está amplamente representada na primeira dessas coalizões - Janata - que governa após a partida de Indira Ganhi.

As múltiplas reviravoltas dessa história foram suficientemente descritas ${ }^{43}$ e quase não é necessário retomar essa questão. Em

38. Mesmo que o Partido do Congresso domine o campo político, há divergências internas quanto às questões de reforma agrária, particularmente em nível dos estados, que detêm essa competência. H.C.L. Merillat salienta que "em nível estadual, a política é dominada pelos latifundiários e pelos produtores rurais abastados" (ibid., p. 297).

39. "Limitando-se estritamente a um raciocínio puramente jurídico e a uma interpretação puramente formal e técnica da Constituição, as jurisdições bloquearam todos os esforços dos governos sucessivos do Partido do Congresso a favor de mudanças econômicas ou sociais. Essa rigidez das instâncias superiores encorajou os dirigentes estatais a tentar enfraquecê-las ou contornar essa obstrução.", L. I. Rudolph, S. Hoeber Rudolph, In Pursuit..., op. cit. p. 104.

40. Trata-se do exame da conformidade da lei à Constituição pelo juiz.

41. Com a sentença Golak Nath de 1967. Em 1973, outra sentença vem matizar e também reforçar essa afırmação, enunciando que o Parlamento deve respeitar as basic structure ou essential features da Constituição. Os juizes do Supremo se reservam, é evidente, o poder de precisar o conteúdo dessas noções, para verificar se o Parlamento ultrapassou seus direitos (L. I. Rudolph, S. Hoeber Rudolph, In Pursuit..., op. cit. p. 110).

42. 0 Presidente do All India Bar teria declarado publicamente: "Pedia-se a ele que se curvassem e eles se deitaram!".

43. A melhor sintese é aquela de L. I. Rudolph, S. Hoeber Rudolph em In Pursuit..., op. cit., mas também se podem consultar as análises de profissionais mais diretamente envolvidos nessas lutas: Upendra Baxi, The Indian Cour suprême and Politics, Lucknow, India, Eastern Book Company, 1980; R. Dhavan, “Judges...”, op. cit. ; S. K. Verma Kusum (éd.) Fifty Years of the Cour Supreme of India, Its Grasp and Reach, New Dehli, Oxford University Press, Indian Law Institute, 2000. 
contrapartida, sua interpretação levanta algumas questões, principalmente porque esses comentários são, na maioria das vezes, escritos ou inspirados por membros da elite. De fato, seja qual for seu objetivo - encorajar o ativismo desta rights revolution ${ }^{44}$ ou, ao contrário, destacar os perigos de uma atitude aventureira no campo político - todas essas análises endossam mais ou menos o postulado de uma Corte Suprema distinta e distante do político. Aliás, a própria imagem do pêndulo ilustra esse postulado, enquanto aparentemente demonstra seu fundamento: já que o enfraquecimento do político coincide com a afırmação da autoridade da corte, e vice-versa, isso não é a melhor prova de que são entidades distintas?

No entanto, essa evolução em sentido inverso também pode ser interpretada como o efeito de uma complementariedade que resulta de sua estreita ligação por intermédio do duplo papel dos notáveis do Judiciário. Depois de se terem aventurado durante um tempo na política para tirar partido das oportunidades oferecidas pela construção das instituições de Estado, esses notáveis se voltam para o campo do direito para se distanciar do intervencionismo de um socialismo de Estado, tão pouco conforme a seu habitus profissional quanto hostil aos interesses de seus clientes e aliados políticos. Assim, em 1970, a Suprema Corte invalida as medidas de nacionalização dos 14 maiores bancos, que acabam de ser tomadas pelo governo de Indira Gan- dhi, assim como aquelas que suprimem os privilégios financeiros dos Príncipes (Privy Purse ${ }^{45}$ ). É claro que, neste caso, trata-se somente de uma tentativa conservadora, visto que o governo acaba por impor sua política. Mas essas escaramuças judiciais permitem ganhar tempo e, sobretudo, preparam o caminho de uma contraofensiva ideológica, quando o confronto se exacerba com a proclamação do estado de emergência. Desacreditados como adversários do progresso e da igualdade, as figuras ilustres do Judiciário e da política reconstroem para si mesmas uma virtude cívica como defensores das liberdades constitucionais.

0 conflito mudou de sentido quando o governo Gandhi, que se mostrara nos anos sessenta campeão de um progresso social bloqueado pelas jurisdições, se viu acusado nos anos setenta de se opor à Corte porque ela se esforçava para restringir os abusos de poder insensatos de um Estado que obedecia apenas à sua própria lógica ${ }^{46}$.

\subsection{0 confronto dos lawyers-políticos no terreno do Judiciário}

Essa representação em termos de oposição entre dois poderes - o político e o judiciário - não corresponde, entretanto, à realidade, visto que os adversários, de ambos os lados, mobilizam recursos que são tanto políticos quanto jurídicos. Dois dos principais protagonistas desse debate constitucional, Nani

44. Ch. R., Rights Revolution..., op. cit.

45. Após um acordo com o primeiro presidente da Índia, Patel Rep Vallabhai, algumas centenas de famílias principescas beneficiaram-se de uma renda anual perpétua de alguns milhões de rúpias (privy purse), garantida pela Constituição em troca do abandono de sua soberania. A abolição desses privilégios fora decidida após as eleições de 1967, em razão da radicalização do partido do Congresso, mas foi instaurada por decreto presidencial devido à oposição do Senado. Essa decisão foi invalidada pela Corte (ibid. p. 108). 46. L. I. Rudolph, S. Hoeber Rudolph, In Pursuit..., op. cit., p. 104. 
Palkhivala e Mohan Kumaramangalam, são juristas ilustrados, que representam polos opostos do campo político. Nani Palkhivala, diretor do grupo Tata, é um renomado advogado comercialista e constitucionalista: publicou, em 1974, a obra Our Constitution profaned and Defiled para denunciar a "profanação" e a "sordidez" da Constituição. Mohan Kumaramangalam, antes de se tornar um dos conselheiros mais próximos de Indira Gandhi até sua morte (1973) $)^{47}$, seguiu, como muitos de seus condiscípulos, uma carreira dupla no direito e na política. Como líder da ala socialista do Partido do Congresso, foi um dos principais mentores da política de nacionalização dos bancos. No entanto, em uma obra teórica de Direito Constitucional - Constitutional Amendments: The reason why (1971) - Kumaramangalam justifica a legitimidade das Vigésima Quarta, Vigésima Quinta e Vigésima Sexta emendas constitucionais, conhecidas como "Kumaramangalam package", que contradizem a sentença Golaknath pela qual a Corte havia afirmado sua autoridade constitucional $^{48}$.

Assim, dificilmente essa luta poderia ser reduzida a uma oposição entre o Parlamento e o alto judiciário. A elite do Judiciário está no cerne desse confronto, que ocorre paralelamente nos terrenos do direito e da política, tornando a mistura desses gêneros inevitável. Os defensores das classes possuidoras mobilizam recursos jurídicos, acarretando uma politização crescente das instituições do campo jurídico e sua transformação em arena do combate político.
Quando o confronto se exacerba com a proclamação do Emergency, são os grandes líderes do judiciário que passam a comandar o movimento de oposição, denunciando publicamente os excessos do poder do Estado, em nome da defesa das liberdades fundamentais. A Corte Suprema, por sua vez, se inclina às exigências do poder. Enquanto isso, Indira Gandhi havia acabado de nomear cinco juízes "politicamente engajados" - que se tornariam depois os líderes de um ativismo social - e de impor, ao mesmo tempo, seu candidato como Chief Justice, a despeito do princípio de promoção por antiguidade até então respeitado.

\section{Rumo a uma divisão do trabalho no cam- po jurídico e no campo do poder}

Apesar da forte homogeneidade social dos notáveis do Judiciário, a violência dos confrontos políticos consegue quebrar o consenso tácito que lhes permitia investir na política, preservando o mito da neutralidade das instituições jurídicas. Ao mesmo tempo, essa crise lhes dá a formidável oportunidade de restaurar seu capital político, já bem menor, ao reproduzir a estratégia tão bem sucedida usada por seus antecessores nas lutas de independência. Esse mimetismo vai longe: de acordo com um de nossos interlocutores, é na prisão que esses lawyers $^{49}$ lançam as bases de um novo partido do governo - o Janata - que servirá como suporte das estratégias desses notáveis no campo político.

47. É possível que a morte desse grande jurista, muito influente para Indira Gandhi, tenha contribuído para a disputa que culminou na proclamação do Emergency.

48. L. I. Rudolph, S. Hoeber Rudolph, In Pursuit..., op. cit., p. 111.

49. Entre os quais se encontram, entretanto, diversos membros antigos do Congress, em oposição às orientações socialistas de Indira Gandhi ou prejudicados pelos métodos do filho Sanjay, para criação de uma clientela de jovens políticos tão devotos quanto pouco escrupulosos (ibid., p. 85 e 140). 
De fato, com a derrota eleitoral de Indira Gandhi, em 1977, essas personalidades do Judiciário voltam ao primeiro plano do campo político. No entanto, essa primeira tentativa de restauração da aristocracia política dura pouco: a coligação heteróclita que ela constituiu para se opor ao Partido do Congresso não resiste muito tempo às intrigas de palácio entre gerontocratas. Os dois grupos não hesitam em levar suas rixas aos tribunais, acusando um ao outro de corrupção. Todavia, esse modelo dos juristas-políticos perdura, seja no retorno da dinastia Gandhi e do Partido do Congresso $\mathrm{I}^{50}$ ao poder em 1980, seja nas coligações que o sucederam a partir do fim dos anos

\section{Um estadista do Direito}

Assim, o Ministro da Justiça no poder na época de nossa pesquisa deve sua notoriedade principalmente ao fato de ter sido presidente do All India Bar por cinco mandatos consecutivos durante a crise que culminou no Emergency. Antes disso, esse herdeiro de três gerações de lawyers eminentes jamais havia feito politica. Entretanto, muito jovem, no início dos anos 1950, ele ganha notoriedade graças a uma "famosa causa": pouco depois da partição, quando recém havia fugido de Karachi para Mumbai, como milhões de outras pessoas, ele contesta o Bombay Refugie Act, invocando o respeito aos direitos das minorias inscrito na Constituição. E a Corte lhe dá razão contra o governo de Jawarharlal Nehru. "É a esse acontecimento que devo minha reputação de advogado capaz de convencer um júri. Ganhar um processo dessa envergadura confere autoridade a qualquer um imediatamente. [...] Isso chama a atenção do público, o que é a chave do sucesso no judiciário. [...] É esse tipo de "causa célebre" que dá fama a um advogado, que atrai o foco do público para si. [...] Já o sucesso em processos comerciais chama pouca atenção, mas, por outro lado, traz clientes...”. Essa fama lhe rende uma banca próspera, que ele combina a uma atividade de docência; também lhe confere visibilidade junto aos pares, que o elegem em 1964 para o Bar Council de Mumbai e, em seguida, para o All India Bar Council, do qual passa a ser presidente a partir do começo da década de 1970. "Quando o estado de emergência foi decretado, não fiquei em silêncio. [...] Em uma reunião do judiciário, ataquei violentamente Indira Gandhi e seu filho. [...] Finalmente eles decidiram reagir, e recebi um mandado de prisão. [...] Quando 300 colegas meus se apresentaram na High Court de Mumbai em minha defesa, os juizes ordenaram a não execução do mandado. Com esse julgamento no bolso, pude continuar minha viagem por todo país, atacando Indira Gandhi. [...] Até que, finalmente, a mais alta jurisdição sucumbe e profere a mais ignóbil das sentenças: os tribunais não podem mais assegurar a proteção dos direitos humanos enquanto o estado de emergência estiver instaurado. [...] Antes da meia-noite, o próprio chefe da polícia me coloca em um avião para fugir do país." (entrevista). Após um breve período de exílio nos Estados Unidos, onde mobiliza as ONGs e a banca jurídica, retorna de modo triunfal à Índia na ocasião das eleições de 1988, quando vence o ministro da justiça de Indira Gandhi. A partir de então, segue uma dupla carreira como político e líder do judiciário. Baseado nisso, afırma ser "um grande incentivador do ativismo judiciário", ainda que tenha perfeita consciência de que se trate de uma tentativa de reabilitação: "Os juizes fazem penitência por seus pecados [...] Eles reagem para apagar um passado vergonhoso”. Aliás, essa figura eminente toma cuidado para mostrar distanciamento em relação à ideologia radical pregada por esses juizes "politicamente engajados", nomeados por Indira Gandhi, principalmente um dos membros mais importantes, que ele chega a qualificar como "comunista notório".

50. Esse Congress I (I de Indira) se opõe ao "paternalismo, assim como a essa mentalidade aristocrática "noblesse oblige" - características das castas superiores (twice-born) que dirigem o Congress $O$ ( 0 de organização)" (ibid., p. 168). 
1980. Embora os lawyers tenham perdido o monopólio quase total de que gozavam nos primeiros anos da República, eles ainda detêm quase um terço das cadeiras no Parlamento; além disso, suas posições se fortalecem à medida que sobem na hierarquia do poder político: 50\% dos cargos de gabinete ministerial e 67\% dos ministros, em $1985^{51}$. Ainda hoje, os líderes da Corte Suprema se vangloriam por serem bem representados no gabinete do Primeiro Ministro por companheiros eminentes que levam a essas coligações, predominantemente populistas, todo seu capital social de grandes personalidades do Estado.

Embora tenha reatado suas relações com o poder, a elite do Judiciário não negligenciou as instituições do direito responsáveis por seu retorno à cena política. Sob a influência dessa elite, o governo Janata se engaja na restauração da independência do poder judiciário ${ }^{52}$ e na restauração de sua autoridade em matéria constitucional. No entanto, essas promessas não foram cumpridas por causa das disputas internas des- sa coligação heteróclita. Paradoxalmente, é em 1980, após o retorno de Indira Gandhi ao poder, que a Corte Suprema reconsidera as concessões feitas durante o estado de emergência e se lança, depois, em um ativismo paternalista em favor dos mais desfavorecidos e das vítimas de abusos de violências policiais: implementa uma nova política, a Public Interest Lawyering (PIL), que facilita a impetração de recursos aos ativistas dos movimentos sociais. A maioria dos estudiosos caracteriza essa "busca populista de legitimação como uma tentativa da elite do judiciário de restaurar sua reputação, em seu pior momento junto à opinião pública devido à aprovação dada pela Corte aos abusos de poder cometidos durante o estado de emergência ${ }^{53}$ ”. Em compensação, eles quase não levam em conta os recursos políticos que foram mobilizados para que a empreitada de restauração da autoridade judiciária fosse bem sucedida.

Dois dos principais protagonistas desse ativismo judiciário - os juízes Krishna Iyer e Prafullachandra Bhagwati ${ }^{54}$ - foram

51. Ver J. S. Gandhi, “Past and Present...”, op. cit., p. 369-382. Mesmo que essas porcentagens reflitam em grande parte um efeito de geração (os lawyers dos gabinetes ministeriais provêm, no caso da maioria dos representantes da velha geração, das lutas de independência), elas continuam sendo, entretanto, significativas. Isso porque as vias de acesso às carreiras estatais ou politicas se multiplicaram, enquanto a oferta do Judiciário continua muito limitada por um modo de reprodução familiar e bastante elitista. Além disso, esse tipo de carreira se torna menos rentável em razão da fragilidade das coligações governamentais, que acelera a renovação (turn-over) dos quadros políticos e, sobretudo, mais arriscado: "No começo dos anos 1990, um número sem precedente de ministros foi acusado de corrupção, tanto em nível federal quanto em nivel estatal", L. I. Rudolph, S. Hoeber Rudolph, "Redoing the Constitutionnal Design: From an Interventionist to a Regulatory State”, in Atul Kohli, (ed.), Against the Odds; India's Democracy at Fifty, Cambridge University Press, 2000.

52. Especialmente ao reatar com a seniority rule, sob o risco de nomear como Chief Justice um dos aliados de Indira Gandhi. (L. I. Rudolph, S. Hoeber Rudolph, In Pursuit..., op. cit., p. 116).

53. Ch. R. Epp, Rights Revolution..., op. cit., p. 85. R. Dhavan considera “esse período de revalorização e de promoção da autoridade judiciária espetacular por dois motivos: a Corte consegue com isso não só restaurar sua imagem quando esta estava bastante degradada, mas também se tornar uma das instituições chave do novo regime de governo (governance)" (“Judges...”, op. cit., p. 331).

54. Ver P. N. Bhagwati, “Judicial Activism and Public Interest Litigation” Columbia Journal of Transnational Law, vol. 23, 1985, p. 561. 
nomeados por Indira Gandhi, aconselhada então por Kumaramangalam, para compor a Corte devido a seu engajamento político. Ao expressar publicamente suas convicções e fidelidade políticas ${ }^{55}$, esses juízes manobram de maneira bastante hábil para recuperar o prestígio da Corte e afirmar - com prudência - sua autoridade, sem correr o risco de sofrer represálias do poder ${ }^{56}$. Para o governo, esse tipo de ativismo é pouco ameaçador, visto que denuncia, principalmente, as exações e abusos do poder cometidos pelos escalões mais baixos do aparelho do Estado - policiais, carcereiros, etc. com as castas inferiores. De resto, a justiça social deixa de ser a prioridade do governo de Sanjay Gandhi, um regime marcado pelo anticomunismo e voltado para uma política de abertura econômica e de desregulamentação, mais de acordo com o credo neoliberal da década de 1980.

A habilidade dessa estratégia está em contradizer os políticos e as personalidades do direito por meio do questionamento de seu próprio discurso, ainda que esse não seja atual, e lembrar que Indira Gandhi havia conseguido desqualificar a Corte Su- prema na época do estado de emergência, denunciando-a como "inimiga do desenvolvimento e dos pobres" 57 .

Assim, ao neutralizar a potencial hostilidade dos políticos e dos advogados, os juízes radicais da Corte Suprema se aliam às novas camadas urbanas e trabalhadoras, que, após terem se mobilizado pela defesa dos direitos civis na época do estado de emergência, se reconvertem ao ativismo social, passando a compor ONGs. De acordo com uma estratégia tão antiga quanto universal ${ }^{58}$, essa empreitada pretoriana para expandir o domínio de intervenção da Corte acompanha o esforço para aumentar a base social da elite do Judiciário para além do círculo mágico dos herdeiros, criando laços com os representantes mais empreendedores de uma nova meritocracia profissional, ainda pouco reconhecida pelo establishment.

Desse modo, diversos membros da Corte Suprema apoiam a criação de uma nova Law School, cujo objetivo seria, ao menos inicialmente, gerar uma nova meritocracia de ativistas do direito. Planejada para responder aos critérios de financiamento impostos pela política reformista da Fun-

55. L. I. Rudolph, S. Hoeber Rudolph citam (In Pursuit..., op. cit., p. 108) duas declarações publicadas pela revista Statesman em abril de 1980, pouco após o retorno de Indira Gandhi ao poder: Para Lyer, "o direito, tal como foi pensado pelos britânicos, ou seja, com o objetivo de servir aos interesses de classe, não é apropriado às atuais condições sociais da Índia”. Já P. N. Bhagwati, futuro Chief Justice, não hesita em bancar o sicofanta de Indira Gandhi: "Estou certo de que, com vossa vontade de ferro, vossa determinação, vosso instinto acurado, vossa visão de futuro, vossa competência administrativa e vossa vasta experiência, mas também com o amor e a afeição irresistiveis de vosso povo, [...] Vossa Excelência será perfeitamente capaz de dirigir o Estado, lutando pelos objetivos que todos almejamos [...]".

56. "Como a concepção de ativismo judiciário da Corte podia ser integrada à agenda populista dos governos de Indira (1980-1984) e de Rajiv (1985-1989), nenhum dos dois primeiros-ministros do Congress viram no PIL (Public Interest lawyering) uma ameaça à soberania parlamentar reivindicada por seu partido" (L. I. Rudolph, S. Hoeber Rudolph, “Redoing...”, op. cit.).

57. R. Dhavan, “Judges...”, op. cit., p. 314.

58. R. Dhavan (ibid. P. 317) lembra a concepção bastante antiga do papel social do juiz na Índia, que devia ser uma espécie de consciência moral do chefe, mantendo-se consciente dos limites de sua autoridade simbólica: "evitar qualquer confronto direto" em prol de "críticas discretas". 
dação Ford e pelos universitários norte-americanos que a aconselham, essa escola acaba respondendo apenas parcialmente às ambições de seus criadores. Uma seleção escolar rigorosa e uma formação de qualidade fizeram dela, de fato, a incubadora de uma nova meritocracia profissional, bastante distinta dos herdeiros gerados pelos círculos familiares. No entanto, entre esses diplomados, poucos são os que têm vocação ao ativismo. Essa nova elite encontrou apenas um nicho precário nos novos gabinetes de negócios aos quais fornece uma mão-de-obra competente, mas cuja promoção entra em choque com uma "redoma de vidro" que reserva aos herdeiros as vias de acesso à hierarquia do campo.

0 ativismo social da Corte vai ao encontro de uma relativa prudência no campo político. A Corte rejeita educadamente cerca de vinte processos contra Indira e Sanjay Gandhi ou seus colaboradores devido aos abusos de poder cometidos durante o estado de emergência. E, para manter a coerência, rejeita simultaneamente as perseguições feitas aos dirigentes do partido Janata. Embora reafırmada em seu princípio, a implementação da autoridade constitucional da Corte é feita com grande prudência.

Podemos, então, questionar em que medida a grande visibilidade ${ }^{59}$ desse ativismo social tão midiático não teve como função servir de álibi a estratégias de acordos no campo político - estratégias que permitiam à elite do judiciário seguir discretamente um duplo jogo político e jurídico que lhes foi tão proveitoso. Nesse sentido, é significativo que a Corte Suprema tenha se envolvido apenas relativamente - exceto de modo indireto nos casos de corrupção - nos debates políticos e nos conflitos sociais que acompanham o processo de abertura e de desregulamentação que vem se acelerando há uma década. Segundo o ministro da justiça, "a Corte reiterou que os tribunais e os juízes não devem se envolver nas orientações da política econômica a não ser com extrema reticência”. Ele reconhece, entretanto, que essa atitude de reserva não é algo evidente: "pois o socialismo inscrito na Constituição impõe ao Estado uma obrigação permanente de responsabilizarse pelas necessidades das camadas sociais menos favorecidas", afirma. No entanto, o desmantelamento - ainda muito parcial do intervencionismo do Estado se dá, em sua essência, fora da arena judiciária, embora todos os recursos do direito tenham sido mobilizados contra essas políticas. A elite do Judiciário se aproveita demais das consequências comerciais desse processo de liberalização da economia, para que seus adversários sequer imaginem fazer uso de suas competências para se opor a ela.

\section{Considerações finais}

Neste esboço da história estrutural da Corte Suprema, privilegiamos a esfera política. Entretanto, a incrivel prosperidade dos juristas comerciais graças à liberalização econômica está aí para nos lembrar que essa elite profissional jamais sacrificou o desenvolvimento do seu mercado às suas ambições políticas. 0 máximo que ela fez foi se esforçar, com maior ou menor sucesso, conforme a época, para conciliar essas duas preocupações.

59. Principalmente no mundo anglo-saxão, onde a promoção do PIL é assegurada por juristas indianos, como U. Baxi ou R. Dhavan, seus autores, após terem contribuído para essa importação. 
Essa constatação - que certamente não se restringe à Índia! - deveria nos incitar a superar essa falsa alternância entre as teorias que privilegiam as lógicas monopolistas no mercado do Direito - ainda que seja para denunciá-las melhor - e essas novas posturas ideal-típicas que se atêm ao político, descartando a dimensão mercantil. Como se não fosse a correlação desses dois espaços que permita a prosperidade do mercado do direito, ao mesmo tempo que assegura a reprodução do capital de legitimidade social, do qual depende o valor desses bens simbólicos! Além disso, a divisão simbólica do trabalho entre diferentes categorias profissionais ${ }^{60}$ permite gerir as tensões entre essas lógicas tão contraditórias quanto complementares - e isso com mais facilidade porque as alianças e as estratégias familiares criam laços entre esses múltiplos componentes do campo jurídico que encarnam interesses sociais (e/ou profissionais) momentaneamente divergentes.

0 principal mérito heurístico desse exemplo diz respeito ao destaque dado a esse componente familiar do direito. É inútil se questionar sobre as relações complexas entre a política e o mercado profissional se não se levar em conta a lógica sociológica - nesse caso, a lógica da herança - que é o fundamento de ambos. Nesse sentido, o exemplo indiano é sem dúvida particularmente excepcional ${ }^{61}$. Entretanto, mesmo nos países em que se combina com o capital escolar, o capital social herdado permanece uma das variáveis determinantes para a compreensão das estratégias familiares que continuam a estruturar o campo jurídico em suas relações com os diferentes polos de reprodução do poder.

60. Ver Y. Dezalay "Juristes purs et marchands de droit: division du travail de domination symbolique et aggiornamento dans le champ du droit”, Politix, no 10-11, 1990.

61. Nossas pesquisas biográficas mostraram, entretanto, que o peso da herança continua muito forte na maior parte dos países da América Latina ou da Ásia. Ver Y. Dezalay, B. Garth, "Law Lawyers...”, op. cit.; The Internationalization of Palace Wars..., op. cit. 
-1885: Primeira reunião do Partido do Congresso.

-1907: Motilal Nehru, líder da ala moderada do Partido do Congresso.

-1920: Primeiras campanhas de boicote influenciadas por Indira Gandhi.

-1947: Partição e independência da Índia e do Paquistão. Jawarharlal Nehru se torna primeiro-ministro.

-1950: Corte Suprema invalida as leis de reforma agrária.

-1951: Primeira emenda constitucional: a reforma agrária contraria os princípios constitucionais.

-1964: Morte de Jawarharlal Nehru.

-1966: Indira Gandhi se torna Primeira-ministra.

-1967: Sentença Golak Nath: o Parlamento não pode modificar os princípios constitucionais.

-Julho de 1969: Nacionalização dos 14 bancos principais.

-Novembro de 1969: Cisão entre a "velha guarda" dos partidários de Morarji Desai, no Congress, e os que continuam fiéis a Indira Gandhi.

-1970: A Corte anula a nacionalização dos bancos e a abolição dos privy purse por inconstitucionalidade.

-12 de junho de 1975: Indira Gandhi é destituída de seu mandato pela High Court de Allahabad por irregularidades durante as eleições de 1971. Após ter considerado demitir-se, Indira Gandhi decide lutar, considerando que essa decisão não é executória, no aguardo de uma apelação à Supreme Court.

-25 de junho 1975: Proclamação do estado de emergência e prisão de seiscentos líderes de oposição, entre eles Morarji Desai, que havia lançado um chamamento à transferência de Indira Gandhi.

-21 de março de 1977: Derrota eleitoral de Indira Gandhi põe fim ao estado de emergência.

-Janeiro de 1980: Indira Gandhi retorna ao poder após a derrota eleitoral da coligação Janata.

-Maio de 1980: A Corte Suprema reafirma seu poder constitucional, inscrevendo-o nos limites que ela mesma define.

-31 de outubro de 1984: Assassinato de Indira Gandhi, substituida por seu filho Rajiv.

-21 de março de 1991: Assassinato de Rajiv. 
RESUMO

A construção legal de uma política de notáveis. A história do Bar Indiano ilustra os fatores sociais que determinam o entrelaçamento entre direito e política - assim como seus altos e baixos. Assim, a mobilização do Bar contra o estado de emergência imposto por Indira Gandhi não foi suficiente para restaurar seu crédito político, obtido durante as lutas pela independência e perdido por conta da sua oposição às reformas agrárias. Por outro lado, ao tornarse a heroína dos desprivilegiados, a Suprema Corte emergiu como o árbitro de querelas políticas. Isto pode ser visto como uma divisão simbólica do trabalho no campo do poder.

PALAVRAS-CHAVE:

Direito. Política. Campo do Poder. Índia

\section{ABSTRACT}

The Legal Construction of a Policy of Notables. The story of the Indian bar illustrates the social factors determining the close intertwining of law and politics - as well as its ups and downs. Thus, the mobilisation of the bar against the state of emergency imposed by Indira Gandhi did not suffice to restore her political credit, earned during the struggle for independence and lost in her opposition to agrarian reforms. On the other hand, by becoming the champion of the disadvantaged, the Supreme Court emerged as the arbiter of political jousting. This can be seen as a symbolic division of labour in the field of power.

\section{KEYWORDS}

Laws. Politics. Field of Power. India. 
